\title{
cubiertas de plástico reforzado
}

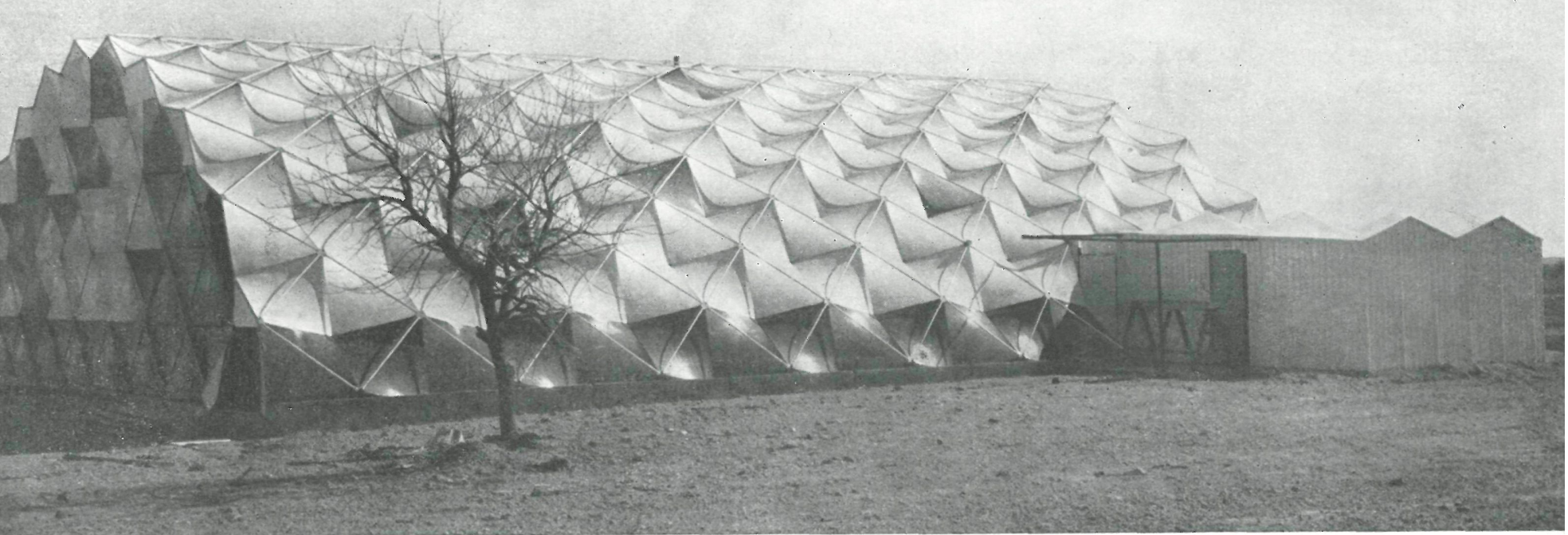

$886 \cdot 2$

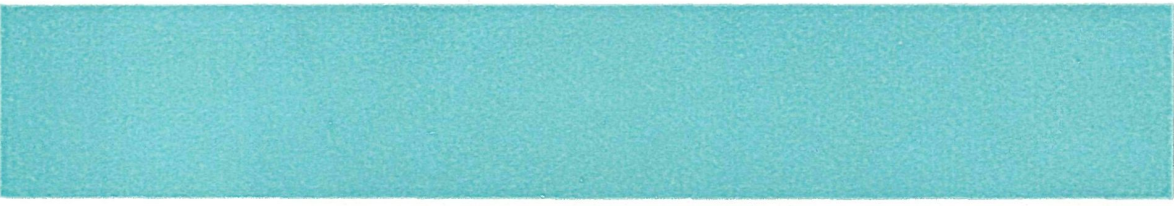

La casa Strutural Plastics Inc. de Fort Worth, Texas (EE. UU.), ha fabricado los materiales utilizados para cubrir una superficie de $700 \mathrm{~m}^{2}$ con un producto plástico, de fibra de vidrio reforzada.

Este material consiste en losetas parabólico-hiperbólicas, de $1,20 \times 1,20 \times$ $\times 0,45 \mathrm{~m}$, que constituyen la base de cada fila de elementos que forman un arco. La reunión de arcos, así formados, componen el todo de la cubierta.
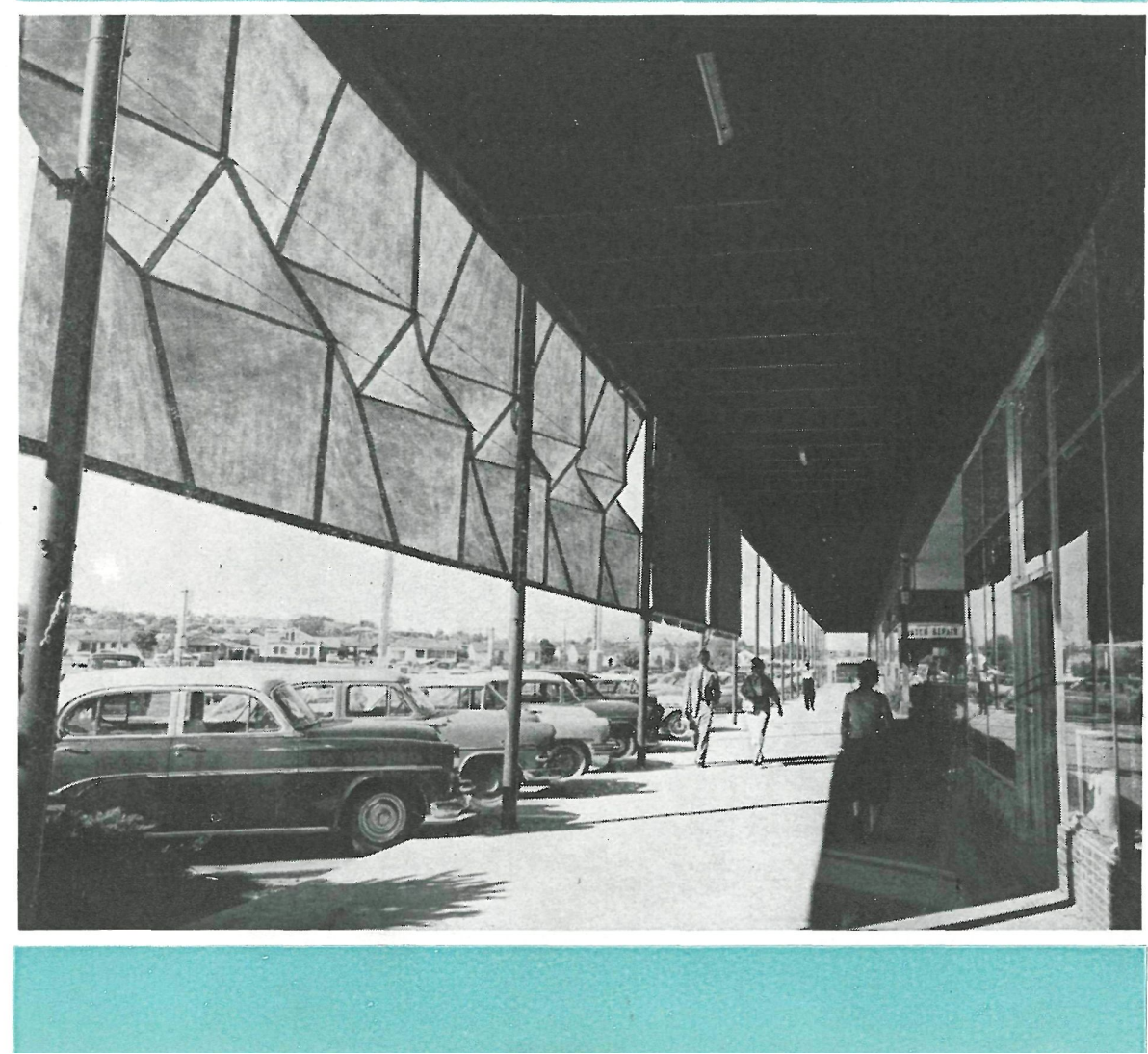

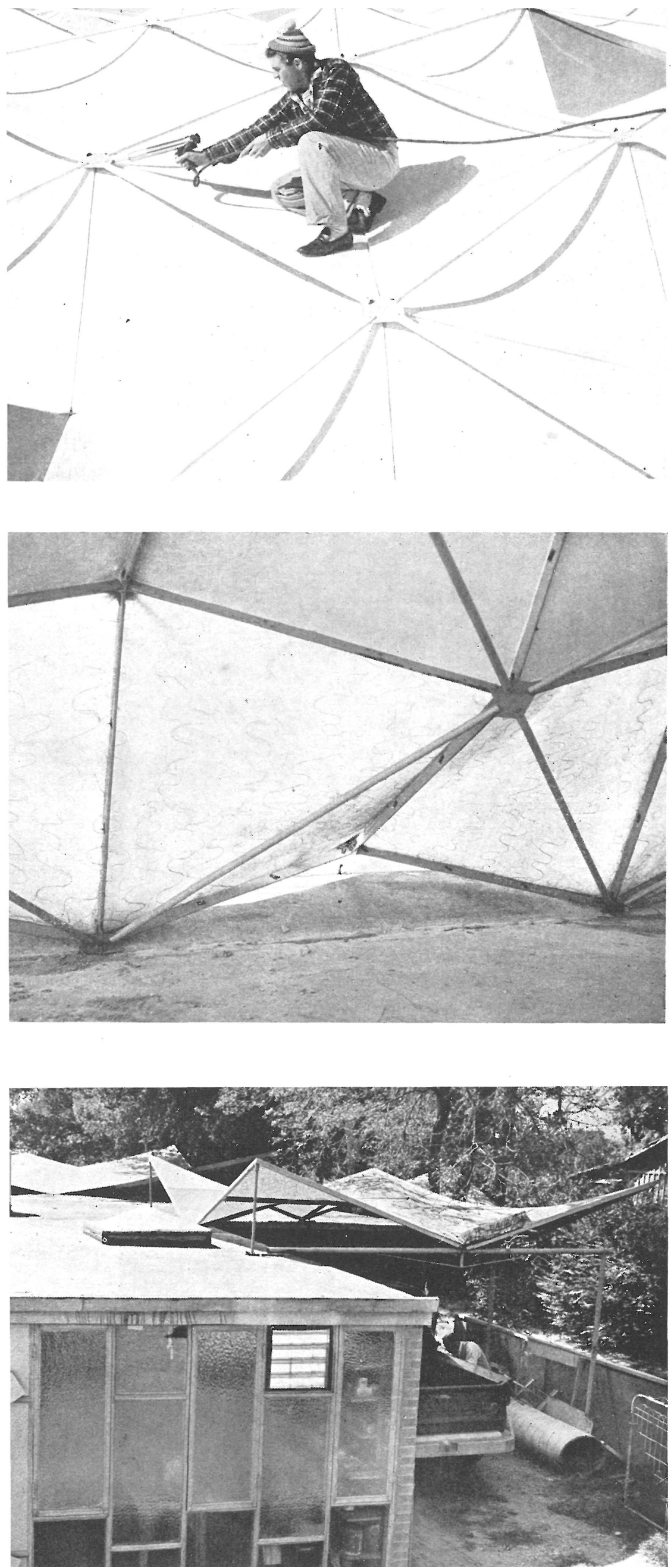

Los elementos se agrupan de cuatro en cuatro apoyándose en un ligero armazón que sirve de unión y armadura de las placas parabólico-hiperbólicas. La forma de bóveda se mantiene por medio de tirantes metálicos que constituyen el arriostramiento general.

El montaje de este tipo de cubiertas, $\sin$ apoyos intermedios, es muy senci1lo. Consiste en unir los elementos que constituyen un arco en el suelo, levantarlo después con gatos y fijarlo finalmente en posición.

Una particularidad atribuída a este tipo de formas, consiste en crear un régimen turbulento en la corriente de viento que choca contra ella, lo que da lugar a una seguridad contra los posibles efectos de la subpresión que, de otra forma, podría originar el levantamiento de la cubierta.

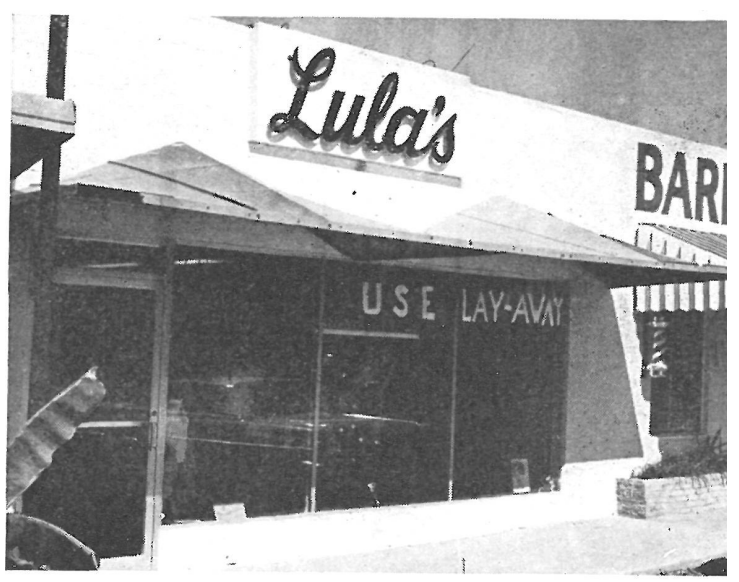

Las indudables ventajes económicas y técnicas-resistencia, impermeabilidad, ligereza, facilidad de acoplamiento, etc.-de estas formas ya industrializadas, hacen que cada día se amplíen sus campos de aplicación, tanto en la construcción de elementos abovedados de cierta importancia como en pequeños elementos funcionales y decorativos: marquesinas, toldos, cerramientos...

Fotos: LEE ANGLE 